\title{
Improved Fuel Economy of Through-the-Road Hybrid Electric Vehicle with Fuzzy Logic-Based Energy Management Strategy
}

\author{
Mohamad Faizrizwan Mohd Sabri ${ }^{1,2}$ (D) Kumeresan A. Danapalasingam ${ }^{2}$. \\ Mohd Fua'ad Rahmat ${ }^{2}$
}

Received: 7 August 2017/Revised: 17 April 2018/Accepted: 26 June 2018/Published online: 18 July 2018

(c) Taiwan Fuzzy Systems Association and Springer-Verlag GmbH Germany, part of Springer Nature 2018

\begin{abstract}
Hybrid electric vehicle (HEV) provides drivers with uncompromised drivability while significantly reducing hazardous emissions. This is achieved through optimal power flow solution via energy management strategy (EMS) which efficiently handles energy distribution from the different energy sources of a HEV. In this paper, a through-the-road (TtR) HEV configuration with fuzzy logic-based EMS is proposed. Fuzzy logic is applied in the main control block of the vehicle with a pair of membership functions assisting the power flow controller to select the appropriate power distribution by the hybrid drivetrain based on available resources in real time. The EMS operates in hybrid mode blended control strategy to achieve minimum fuel consumption for the desired trip by prioritising the electrical drivetrain over the internal combustion engine (ICE) for power distribution to the wheels. A Simulink model was constructed in MATLAB ${ }^{\circledR}$ to represent the TtR HEV equipped with in-wheel motors (IWM) in the rear wheels. A fuzzy logic-based EMS controller has been synthesised. The power flow in the TtR HEV is decided based on current vehicle speed and the global discharge rate (GDR) value derived from the current stateof-charge (SOC) of the battery and remaining trip distance. The proposed controller performs well on standard drive cycles and offers up to $62 \%$ improvement in fuel consumption compared to the reference model which uses rule-based EMS. Comparisons against other published
\end{abstract}

Mohamad Faizrizwan Mohd Sabri

msmfaizrizwan@unimas.my

1 Universiti Malaysia Sarawak, 94300 Kota Samarahan, Sarawak, Malaysia

2 Universiti Teknologi Malaysia, 81310 Skudai, Johor, Malaysia models are equally encouraging, especially on high average speed drive cycles with up to $19.8 \%$ improvements in fuel consumption.

Keywords Hybrid electric vehicle · Energy management strategy · Through-the-road HEV · Fuzzy logic-based EMS · Hybrid mode blended control strategy

\section{List of Symbols}

$g \quad$ Gravitational acceleration $=9.81 \mathrm{~m} / \mathrm{s}^{2}$

$\beta \quad$ Road incline angle

$m \quad$ Vehicle total mass

$V_{x} \quad$ Longitudinal vehicle velocity

$V_{W} \quad$ Wind speed (+ for headwind, - for tailwind)

$n \quad$ Number of wheels on each axle

$F_{x f}, F_{x r} \quad$ Longitudinal forces on front and rear wheels at ground contact points

$A_{F} \quad$ Effective frontal vehicle cross-sectional area

$C_{d} \quad$ Aerodynamic drag coefficient

$\rho \quad$ Mass density of air $=1.18 \mathrm{~kg} / \mathrm{m}^{3}$

$F_{z f}, F_{z r} \quad$ Normal forces acting on front and rear wheels at ground contact points

$h \quad$ Height of vehicle's centre of gravity above the ground

$F_{d} \quad$ Aerodynamic drag force

$a, b \quad$ Distance of front and rear axles, respectively, from centre of gravity

$V_{\text {batt }} \quad$ Battery voltage

$E_{0} \quad$ Battery constant voltage

$K \quad$ Polarisation constant

$Q \quad$ Battery capacity

$i t=\int i \mathrm{~d} t \quad$ Actual battery charge

A Exponential zone amplitude

$B \quad$ Exponential zone time constant inverse 